\title{
perifèria
}

Número 12, junio 2010

www. periferia. name

\section{Notas en torno a Paisajes, Espacios y Territorios}

\author{
Jorge Grau Rebollo - Universitat Autònoma de Barcelona ${ }^{1}$
}

\begin{abstract}
Ellison, Nicolas; Martínez Mauri, Mònica (Coords.) (2009) Paisajes, Espacios y Territorios. Reelaboraciones Simbólicas y Reconstrucciones I dentitarias en América Latina. Quito: Ediciones Abya-Yala, 228 páginas.
\end{abstract}

\section{Contraportada del libro}

“En antropología se hace necesario anclar los análisis en trabajos etnográficos que den cuenta de los cambios actuales en la relación que una sociedad determinada mantiene con su medio. A esta escala es posible entender las relaciones entre percepciones, prácticas y representaciones ecológicas, al mismo tiempo que se puede clarificar la adopción, adaptación o rechazo de las dinámicas globales en las prácticas cotidianas. A esta escala etnográfica es donde mejor se puede ver cómo el entorno ecológico, o el paisaje en su sentido amplio - tal y como se utiliza en el mundo anglosajón-, proporciona un contexto para la vida humana, incorpora una relación entre la realidad que se vive y la posibilidad de otras formas de ser, y se adapta a las condiciones en las que se desarrolla el día a día y a las condiciones metafísicas, imaginadas o idealizadas (Hirsch, 1995). Y a la escala de lo cotidiano, nos será fácil identificar el rol y la influencia de los agentes mediadores entre el ámbito local, nacional o internacional. Estas mediaciones culturales, políticas que marcan la percepción de los lugares y su articulación en un espacio idealizado, la importación de ideas estetizantes y las demandas políticas sobre el territorio, no deben ser obviadas a la hora de analizar la construcción del paisaje, el territorio y el espacio en la América Latina de hoy".

Paisajes, Espacios y Territorios se presenta como el resultado de un Simposio celebrado en Sevilla en 2006, en el marco del LII Congreso Internacional de Americanistas y reúne diez aportaciones estructuradas, como veremos, en tres partes. Los propios coordinadores presentan la obra como un intento de:

\footnotetext{
${ }^{1}$ Enviar correspondencia a: jordi.grau@uab.es
} 


\section{perifèria}

Número 12, junio 2010

www.periferia. name

(...) reflexionar sobre el papel de las representaciones ecológicas en las construcciones actuales de la territorialidad en América Latina, considerando las re-elaboraciones simbólicas inducidas en las situaciones contemporáneas e insistiendo en los contextos de patrimonialización del medio ambiente (Ellison y Martínez Mauri, 2009: 7).

Sin duda alguna, los distintos capítulos que integran las tres partes del libro responden con holgura a este propósito. Es más, presentan al lector un sugestivo elenco de pensamientos, fundamentados en experiencias etnográficas, que aprovechan el locus común que sugiere el título para trascender un panorama basado en la revisión teórica, ya de por sí necesario, para constituir una genuina invitación al conocimiento crítico.

En este sentido, Mònica Martínez Mauri, doctora en antropología social por la UAB y la École des Hautes Études en Sciences Sociales (EHSS), y Nicolas Ellison, doctor en etnología y antropología social también por la EHESS, reúnen en este libro un conjunto de contribuciones que combinan con acierto: (a) debates teóricos que parten de -y cuestionan- concepciones folk sobre "paisaje", "territorio" o "espacio", (b) aproximaciones críticas al sustrato ideológico que alimenta determinadas cosmovisiones acerca del entorno y la relación humana con él, y (c) representaciones que encierran la tensión entre supuestos globales y anclajes locales, la gestión política y económica del patrimonio natural y cultural, o la redimensión identitaria a que conducen ciertos replanteamientos sobre el significado social y alcance simbólico de la tensión entre territorio, espacio y comunidad. Todo ello se acompaña con reflexiones respecto a la centralidad de los procesos de representación, las implicaciones que acarrean determinadas atribuciones de significado, y las apropiaciones simbólicas tanto de nociones de comunidad como de la reivindicación de un pasado y una memoria íntimamente entretejidos que se ofrecen a la mirada y a la interpretación de comunidades indígenas, autoridades gubernativas e instancias académicas. 


\section{perifèria}

Número 12, junio 2010

www. periferia. name

\section{Estructura}

El libro se divide en tres partes diferenciadas, aunque bien trabadas entre sí, constituyendo cada una de ellas, según los propios coordinadores, un "eje comparativo" que permite, en sus propias palabras:

“(..) reflexionar sobre las relaciones entre las dinámicas sistémicas (socioeconómicas y políticas) constitutivas del proceso de globalización y las representaciones del medio ambiente ancladas en prácticas cotidianas, es decir, entre la expansión de valores pretendidamente universales y los procesos locales" (Ellison y Martínez Mauri, 2009: 25).

Como no podía ser de otro modo, Appadurai (1995) sirve de base para el análisis que los distintos autores llevan a cabo en la línea de seleccionar determinados espacios o paisajes como respaldo de las invocaciones, reivindicaciones o representaciones identitarias, vinculando de este modo aspectos geográficos, histórico-culturales, políticos y económicos. Además, cada capítulo está convenientemente sustentado tanto en la experiencia etnográfica de quien lo escribe como en el manejo de la literatura relevante al respecto, lo que confiere solidez a las reflexiones destiladas en cada aportación.

El primer eje comparativo, conformado por tres capítulos, aborda la dualidad global-local desde el punto de vista de las percepciones y representaciones del paisaje tanto por parte de los indígenas como por parte de cronistas, viajeros, colonos, etc. Así, Baré, Mapuche y poblaciones puneñas constituyen lo que podríamos llamar asientos particulares, concretos, sobre los que pivota el discurso.

El segundo eje expone a través de tres casos concretos, Patagonia, Monte Pascal y Bahía, la relación entre identidad y territorio que va más allá de la noción decimonónica de las fronteras, los estados y sus anclajes territoriales, influye en los vínculos entre comunidad, explotación, subsistencia y territorio, e incluso alcanza la dimensión culturalista de ciertos discursos ecologistas que exhortan, entre otras cosas, al reconocimiento estatal del patrimonios naturales.

Por último, el tercer aspecto transversal acomete la interconexión entre la noción de aborigen, el territorio, la ritualidad y la invocación identitaria que, a través de la tierra "propia" o simbólicamente apropiada, conducen al control de un grupo 


\section{perifèria}

Número 12, junio 2010

www.periferia. name

determinado sobre un espacio concreto.

\section{Localidad(es), identidad(es), significado(s) y poder(es)}

Las derivadas teóricas que pueden extraerse de estas páginas son tan numerosas como fascinantes desde una perspectiva intelectual. Las hebras que emergen de Paisaje, espacio y territorio apuntan, entre otros, a debates acerca de los movimientos ecologistas, la conformación de la identidad, la selección de sus referentes cohesivos, la gestión política de las comunidades o los procesos de representación. Los coordinadores dejan claro que pese a la desterritorialización del discurso y la generalización de flujos económicos globales, las representaciones locales siguen reclamando su espacio (p. 8); por ello, la confrontación de dichas representaciones con nociones culturalmente específicas respecto a "paisaje" o "territorio", pero también su comparación con asunciones folk en referencia a la vinculación entre persona, comunidad, espacio e identidad, refieren, de algún modo, a las consideraciones acerca de la conexión entre localidad y cultura, y a la atenuación de dicho nexo, a las que alude Hannerz (1986: 363), así como a sus consecuencias.

Son ámbitos en los cuales las dicotomías que habitualmente subyacen a los debates teóricos (naturaleza / cultura, propio / foráneo, local / global, espacio físico / espacio simbólico, etc.), se desvanecen ante la urgencia de encarar el análisis desde posiciones intelectuales críticas que se orienten, por ejemplo, a examinar las propias bases sobre las que se asientan. Las proyecciones etnosemánticas han teñido demasiadas veces la aproximación teórica y la interpretación de los hechos. La etnografía aporta en este sentido un conocimiento indispensable e insustituible. $Y$ éste es también un elemento a destacar en el libro: el alimento etnográfico de cada una de las propuestas presentadas. Los conceptos polisémicos o aquellos que se acomodan a distintos usos sin variar su etiqueta constituyen otro riesgo, incrementado por las distintas aplicaciones que pueden operarse desde tradiciones académicas igualmente diversas. Para conjurar este peligro, nada mejor que un recorrido sintético, a modo de genealogía, sobre un dominio, concepto o acepción. También en este sentido encontramos aquí las cautelas oportunas y las revisiones 


\section{perifèria}

Número 12, junio 2010

www. periferia. name

adecuadas.

Aun hay un riesgo adicional, más bien casi una tentación: las consideraciones bienintencionadas. El patrimonio natural, la imagen del indígena como "guardián de la naturaleza", último representante de la relación harmónica con el entorno y el equilibrio natural, el ecologismo como argumento frente a quienes deploran todo lo que lo anteriormente citado representa, no "pueden" estar en cuestión; no "deben" estarlo. Sin embargo, el cuestionamiento al que se someten estas asunciones en Paisaje, espacio y territorio no sólo es necesario sino también profundamente esclarecedor, puesto que en última instancia puede revelarse una nueva forma de contraposición entre las concepciones indígenas y las proyecciones externas que ayude a comprender la razón de algunos desencuentros o malentendidos. Tómese por ejemplo esta reflexión de Maité Boullosa en la tercera parte:

“En este trabajo deseo restituir mis principales interpretaciones sobre los discursos y las prácticas que acompañan la invocación de la Pachamama [la madre tierra]. En primer lugar, intentaré mostrar la instrumentalización identitaria y política que se hace de ella. Confrontaré luego esta instrumentalización con los significados que tiene la Pachamama para los propios campesinos en su vida cotidiana. De esta manera, podremos preguntarnos finalmente si la noción de 'respeto por la naturaleza', preconizada por las organizaciones internacionales en relación a los 'pueblos autóctonos', es en verdad equivalente a la de 'respeto por la Pachamama, la madre tierra', presente en la cosmología local" (2009: 147).

O esta otra de Sansi al final de la segunda:

“(...) la relación del Candomblé con lo que los ecologistas Ilaman 'Naturaleza' es mucho más compleja de lo que estos suponen; en plantas, piedras y lugares sagrados, los practicantes del Candomblé reconocen unas agencias personalizadas con las que entran en un largo proceso de negociación, que podemos caracterizar no sólo en términos de respeto o adoración, sino de mutua apropiación y domesticación“ (2009: 141).

Se nos habla con todo ello no sólo de usos simbólicos o de nociones de territorialización o paisaje, sino también de la gerencia de la acción humana sobre la memoria y el poder, del valor de la etnografía y de la antropología para abordar las diversidades del mundo que habitamos y compartimos $y$ al que nos aproximamos continuamente con el afán de conocerlo y entenderlo, como diría 


\section{perifèria}

Número 12, junio 2010

www.periferia.name

Lévi-Strauss, un poco mejor para actuar un poco menos mal².

\section{Bibliografía}

Appadurai, A. (1995). "The production of Locality" en Fardon, R. (Ed.) Counterworks: Managing the Diversity of Knowledge. Routledge: Londres y Nueva York, pp. 204-225.

Boullosa, M. (2009). “Los usos identitarios de la Pachamama y las creencias en la práctica. El caso de dos pueblos del noroeste argentino" en Ellison y Martínez Mauri (Coords.) (2009) Paisajes, Espacios y Territorios. Reelaboraciones Simbólicas y Reconstrucciones Identitarias en América Latina, Quito: Ediciones Abya-Yala, pp. 147-161.

González Echevarría, Aurora (1987). La construcción teórica en Antropología. Barcelona: Anthropos.

Hannerz, Ulf (1986). "Theory in Anthropology: Small is Beautiful? The Problem of Complex Cultures". Comparative Studies in Society and History, Vol. 28, no 2, pp. 362-367.

Sansi, R. (2009). “Ecologismo, patrimonialización y prácticas de domesticación de lo sagrado en el Candomblé de Bahia" en Ellison y Martínez Mauri (Coords.) (2009) Paisajes, Espacios y Territorios. Reelaboraciones Simbólicas y Reconstrucciones Identitarias en América Latina, Quito: Ediciones Abya-Yala, pp. 127-144.

\footnotetext{
${ }^{2}$ Citado en González Echevarría, 1987: 215-216.
} 